\title{
Roles of prefrontal cortical GABAergic interneurons in psychosis and cognitive deficits in schizophrenia Shoji Tanaka
}

\author{
Address: Dept. of Information \& Communication Science, Sophia University, Tokyo 102-8554, Japan \\ Email: Shoji Tanaka - shoji.tanaka@gmail.com
}

from Seventeenth Annual Computational Neuroscience Meeting: CNS*2008

Portland, OR, USA. 19-24 July 2008

Published: II July 2008

BMC Neuroscience 2008, 9(Suppl I):P36 doi:I0.1 I86/I47I-2202-9-SI-P36

This abstract is available from: http://www.biomedcentral.com/I47I-2202/9/SI/P36

(C) 2008 Tanaka; licensee BioMed Central Ltd.

\section{Clinical background}

Analysis of postmortem brains of patients with schizophrenia from the Stanley Foundation brain collection have shown consistent reduction of reelin, parvalbumin and GAD67, the 67-kilodalton isoform of glutamic acid decarboxylase, in the prefrontal cortex (PFC) and other brain regions [1]. In the PFC, this suggests a decrease in GABAergic inhibition that might be responsible for psychosis. Cognitive deficits are also a core symptom of schizophrenia, which might also be caused by GABAergic dysregulation.

\section{Results}

The PFC circuit of pyramidal neurons and GABAergic chandelier neurons and other GABAergic neurons is implemented with a firing rate model. The dopaminergic modulation of the neuronal activity via D1 receptor activation is essentially the same as in the previous model [2]. Figure 1 shows the time courses of dopaminergic modulation profiles of the pyramidal neurons with different sets of the strength of GABAergic inhibition (see table 1). Without chandelier neurons, hyperactive states readily emerge. Weaker inhibition by other GABAergic neurons enlarges the inverted-U shaped profile to connect it to the hyperactive profile.

\section{Conclusion}

Both chandelier neurons and other GABAergic neurons play critical roles in shaping the dopaminergic modulation profile of PFC activity. Chandelier neurons would suppress hyperactivity with hyper-dopaminergic neurotransmission, which is associated with psychotic states. Other GABAergic neurons regulate the inverted-U shaped profile with moderate levels of dopaminergic neurotransmission, which is important for normal cognitive functions.

Table I: A summary of the variations of the parameter values of the two different types of GABAergic inhibition used in the simulation. The figures in the parentheses indicate the relative strength of the inhibitory action on the pyramidal neurons in the model PFC circuit.

\begin{tabular}{lll}
\hline & chandelier neurons & other GABA neurons \\
\hline A & decreased $(0.0)$ & unchanged $(1.0)$ \\
B & control $(1.0)$ & control $(1.0)$ \\
C & decreased $(0.0)$ & decreased $(0.95)$ \\
D & decreased $(0.0)$ & increased $(1.06)$
\end{tabular}



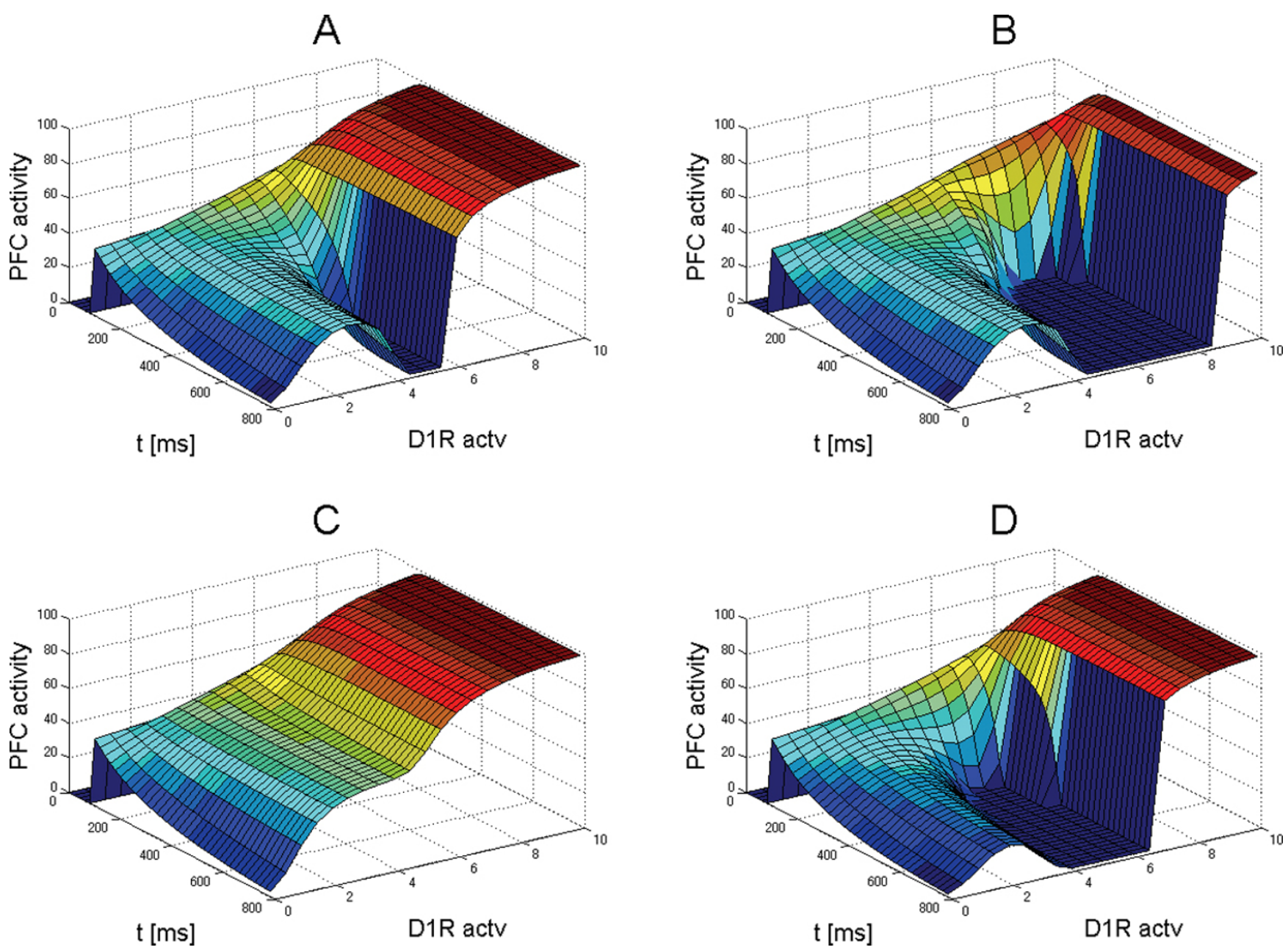

Figure I

Three-dimensional representations of DA modulatory landscapes with (B) and without (A, C, and D) chandelier neurons. Note that the onset of the hyperactive mode is very quick (less than $100 \mathrm{~ms}$ ), whereas the inverted-U mode profiles are very slow to evolve. Even at $t=1000 \mathrm{~ms}$, the profiles of the inverted $-U$ mode have not reached the equilibrium states.

\section{References}

I. Torrey EF, Barci BM, Webster MJ, Bartko JJ, Meador-Woodruff JH, Knable MB: Neurochemical markers for schizophrenia, bipolar disorder, and major depression in postmortem brains. Biol Psychiatry 2005, 57(3):252-260. PMID: I569|526.

2. Tanaka S: Dopaminergic control of working memory and its relevance to schizophrenia: a circuit dynamics perspective. Neuroscience 2006, 139:153-17I. Review. PMID: 16324800.

Publish with Bio Med Central and every scientist can read your work free of charge

"BioMed Central will be the most significant development for disseminating the results of biomedical research in our lifetime."

Sir Paul Nurse, Cancer Research UK

Your research papers will be:

- available free of charge to the entire biomedical community

- peer reviewed and published immediately upon acceptance

- cited in PubMed and archived on PubMed Central

- yours - you keep the copyright
BioMedcentral 